\title{
Enticing for me but unfair to her: Can targeted pricing evoke socially conscious behavior? ${ }^{2}$
}

\author{
Yu Wang ${ }^{\text {a, } 1}$, Aradhna Krishna ${ }^{b, *, 1}$ \\ a Jindal School of Management, The University of Texas at Dallas, USA \\ ${ }^{\mathrm{b}}$ Ross School of Business, University of Michigan, USA
}

Received 2 July 2011; received in revised form 19 November 2011; accepted 23 November 2011

Available online 23 January 2012

\begin{abstract}
Prior research shows that consumers stop purchasing from firms that treat them badly. In this research we show that consumers also resist firms that treat other consumers badly while favoring them. In three experiments, we demonstrate such social consciousness in the context of targeted pricing, where firms offer lower prices to new (versus old) customers. A significant proportion of consumers in our experiments give up money to resist the price-discriminating firm, especially when the discrimination is more salient or is not justified. Further, perceived unfairness mediates the relationship between the salience and justification of the pricing practice and consumer resistance.
\end{abstract}

(C) 2011 Society for Consumer Psychology. Published by Elsevier Inc. All rights reserved.

Keywords: Consumer resistance; Socially conscious behavior; Fairness; Price discrimination; Targeted pricing

\section{Introduction}

Many firms practice discriminatory pricing policies that favor new customers, believing that new customers will view such offers positively. However, can this commonly used marketing tool be considered unfair by potential new customers so that they give up the lower price that favors them? This is the research question we investigate in this paper.

Consumers have been shown to boycott firms that engage in blatant wrong-doing such as using child labor or paying less than minimum wages (Fitzgerald, 1993, John \& Klein, 2003,

\footnotetext{
The authors are grateful to the review team for their constructive comments. The paper also benefited from comments of participants at the INFORMS Marketing Science Conference 2006 at Pittsburgh PA.

* Corresponding author at: R6354 Stephen M. Ross School of Business, University of Michigan, 701 Tappan St., Ann Arbor, MI 48109-1234, USA. Fax: + 17349368715 .

E-mail addresses: yuwang@utdallas.edu (Y. Wang), aradhna@umich.edu (A. Krishna).

${ }^{1}$ Author names are in reverse alphabetic order and the authors contributed equally to the paper.
}

Klein, Smith, \& John, 2004); to stop purchasing from firms that treat them badly, e.g., when firms provide bad service or hide charges in bills (Bechwati \& Morrin, 2003, Sen, Gurhan-Canli, \& Morwitz, 2001); and to voluntarily incur a monetary loss to punish people who violate social norms such as equal division of money, trust and reciprocity (Bolton \& Ockenfels, 2000, Fehr \& Gächter, 1997, Fehr, Gächter, \& Kirchsteiger, 1997).

In all these instances, the avenging or punishing consumers are either negatively affected or are at a disadvantage versus other customers. What has not been shown, therefore, is social consciousness, or consumers taking costly actions because of firms' unethical behaviors, even when they are the favored consumers. More importantly, we show that an everyday marketing context can incite such social consciousness. We bring into question a typical assumption of pricing models (Feinberg, Krishna, \& Zhang, 2002; Villas-Boas, 1999) - that consumer advantaged by differential pricing will always respond positively.

In a series of three experiments, we show that a significant proportion of potential new consumers give up the enticing lower price from the discriminating firm and continue purchasing from their non-discriminating firm due to their perceptions 
of unfairness. Further, such resistance to price discriminating firms is higher when the policy is made more salient, suggesting that advertising these policies or otherwise making them more blatant can backfire. Resistance is also found to be higher when the discriminatory policies are not justified. Additionally, we show that both concerns for one's own future satisfaction and concerns for other disadvantaged consumers can motivate such consumer resistance behavior.

\section{Conceptual framework}

We first distinguish between what we term "self-selected" and "other-selected" price discrimination since the latter alone falls under our definition of targeted pricing and can evoke the consumer responses we predict. In "self-selected" price discrimination, all consumers can avail of the same menu of prices, but it is consumers' actions (e.g., "when" they buy an airline ticket) that results in different prices. In this case, customers are unlikely to think that the pricing is unfair. In "other-selected" price discrimination, however, the firm decides which consumers get a lower price. For instance, Sky (a major digital $\mathrm{TV}$, broadband and phone service provider in the United Kingdom and Ireland) has been implementing differential pricing strategy favoring new customers in the digital TV service market, whereas its competitors (such as Freeview) offer the same price to all their customers. Many consumers face situations such as Sky's and this situation is what we view as targeted pricing and focus on.

Literature on targeted pricing in the last two decades suggests that competitive firms price-discriminating between existing and new customers should offer a lower price to new customers (Fudenberg \& Tirole, 2000, Taylor, 2003, VillasBoas, 1999), assuming that the effect is always positive. However, recent research on price fairness and boycotts suggests otherwise. When consumers perceive unfair prices or unethical marketing practices (Bolton, Warlop, \& Alba, 2003, Darke \& Dahl, 2003), they respond to it by restraining purchases, complaining, spreading negative word-of-mouth and taking legal actions (Bechwati \& Morrin, 2003, Blodgett, Granbois, \& Walters, 1993, Klein et al., 2004, Richins, 1983, Xia, Monroe, \& Cox, 2004). Building on this literature, we propose that:

H1. Consumers advantaged by the targeted-pricing policy may choose to reject the lower price of the discriminating firm, and continue purchasing from their non-discriminating firm at a higher price.

According to the literature on persuasion knowledge, consumers' response to marketing efforts is influenced by their attribution of marketer intent (Brown \& Krishna, 2004, Campbell, 1999, 2007, Friestad \& Wright, 1994). Campbell (1999 and 2007) suggests that inferred firm motive shapes consumers' perception of price (un)fairness. As a result, advantaged consumers in our context may be more negatively inclined to the discriminating firm when its motive is less justifiable.
H2. (Firm motive effect) Consumers are more likely to resist the discriminating firm by rejecting its lower price offer at a cost to themselves, if the firm motive is seen as less justifiable.

Firms often want to blatantly advertise their discriminatory pricing policies to attract advantaged customer. However, a more salient presentation of price discrimination may also appear more unfair. Further, consumers tend to weigh a more salient stimulus more in their judgment and decision making (Krishna \& Johar, 1996, Lalwani \& Monroe, 2005). As such:

H3. (Salience effect) Consumers are more likely to resist the discriminating firm by rejecting its lower price offer at a cost to themselves, if the price discrimination is more as opposed to less salient.

The salience effect is expected to be even stronger if the firm motive is not justified, since in this instance consumers will be even more skeptical of the firm's practices (Brown \& Krishna, 2004, Forehand \& Grier, 2003, Friestad \& Wright, 1994).

H4. (Interaction effect): The salience effect will be even stronger if the firm motive is not justified.

We also propose that the salience effect and firm motive effect are both mediated by consumers' perception of price unfairness. Formally:

H5. Perceived price unfairness will mediate the effect of price discrimination salience/firm motive justification on consumer resistance of the discriminating firm.

\section{Overview of experiments}

Our experiments are carefully designed to measure the likelihood of resistance to price-discriminating firms and the amount consumers will give up. We consider a scenario with two competing firms, each having their current (old) customers and considering the other firm's customers as their potential new customers. Fig. 1 illustrates our experimental setup.

In study 1 and study 2, we allow one "discriminating" firm (DIFF) to offer a lower price to new versus old customers, but let the other "non-discriminating" firm (SAME) charge the same price to all customers. This way, consumers do not have to stop purchasing in order to avoid price unfairness. ${ }^{2}$ In this setting, we expect that some advantaged consumers (those who perceive greater unfairness from targeted pricing) will resist DIFF and will choose to stay with their current firm, SAME, leaving money on the table.

Since there can be strong demand effects for consumers to demonstrate fairness, a direct questioning approach (e.g., "how much would you be willing to give up to resist an unfair firm?") seems unreasonable. We modify a price-until-switching approach (Gonzalez \& Wu, 1999) to measure the amount

\footnotetext{
${ }^{2}$ Models of targeted pricing have also shown that such asymmetries in pricing practices can exist in equilibrium (e.g., Feinberg et al., 2002).
} 
a
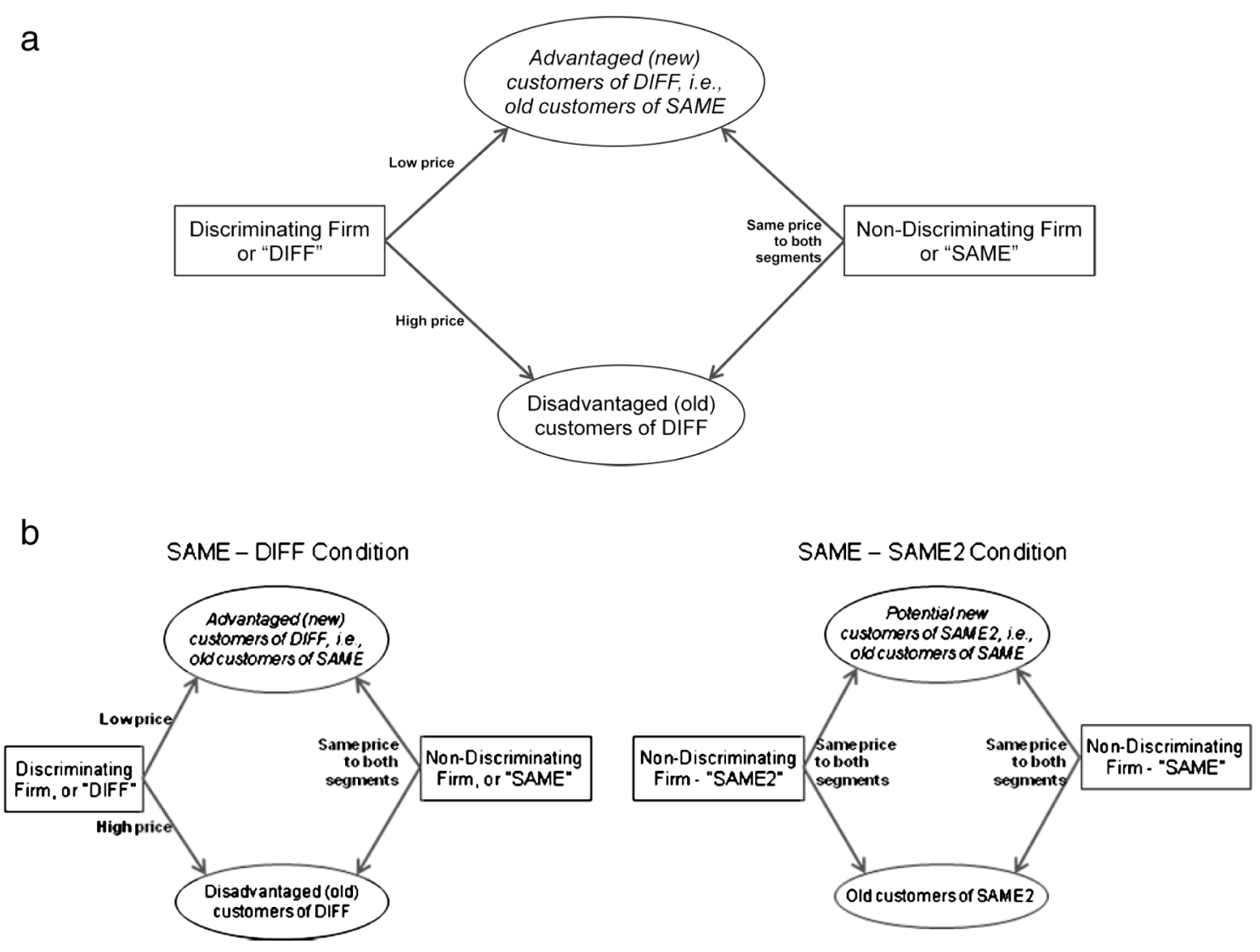

Fig. 1. a: Experimental setup in study 1 and study 2. b: Experimental setup in study 3 .

consumers are willing to give up. Additionally, in study 2 participants bear an actual monetary loss for such resistance, because it is easy to be an armchair ethicist, whereas it is much harder to act on one's stated beliefs bearing a real cost (Alwitt \& Pitts, 1996).

Study 3 uses a more traditional one-decision experimental approach to demonstrate consumer resistance and to uncover some underlying reasons for consumer resistance.

\section{Study 1: Do consumers resist a discriminating firm?}

Two hundred and twenty-seven undergraduate students from a southwest university participated in this study in return for class credit. The study had a 2 (high versus low salience of discrimination) $\times 2$ (justified versus not justified firm motive) between-subjects design.

\section{Procedure}

Each participant was given a questionnaire that started with a cover story about the market, where two firms (NetSpeed and ConnStar) both offered high-speed Internet service. The participants were asked to imagine themselves in the situation given in Exhibit 1.

This situation describes a typical decision that consumers face when offered promotions. Note that to measure resistance to unfairness by advantaged customers, a subject's role was always the potential new customer of DIFF. In the example shown in Exhibit 1, the participant was an old customer of ConnStar (SAME) and a potential new customer of NetSpeed (DIFF). We intentionally allowed participants to make decisions for only next year and not many years to come. Otherwise, subscribing with SAME could be the better choice in the long run, because they could save up to $\$ 28$ for the

Exhibit 1

Situation presented to subjects

Study 1 and study 2

After graduation from the university, you have worked in a regional office of a company for one year. After one more year, you will be transferred to the company's headquarters which is located in a different state. You use a high-speed Internet connection to stay connected with your friends and family. Two reputable firms (ConnStar and NetSpeed) are providing high-speed Internet services in your area. The two services are practically identical to each other in every aspect. For the first year, you purchased from ConnStar. Now you only need another year of service. You know that neither firm offers service in the state where your company's headquarters is, so you will not deal with these firms any more after the end of next year. 
first year with DIFF, but needed to pay $\$ 440$ per year following that which was an $\$ 80$ loss (i.e., $\$ 440-\$ 360$ ). We also controlled the perceived service quality of the firms in order to rule out other potential explanations for our results.

After the cover story, the participants learned about the pricing policies of the two competing firms, and DIFF's motive behind its pricing policy (if in the justified condition). Participants were then asked to make a series of choices between DIFF and SAME on a decision sheet (details follow), then to explain why they made the choices they did, and finally to provide demographic information.

\section{Choice scenarios in the decision sheet}

In the decision sheet, prices offered by the two firms (SAME and DIFF) and the switching cost for consumers were all presented in a single table (see Table 1). The consumer needed to pay a switching cost only if she decided to switch from SAME to DIFF. Switching cost was operationalized as the expense of a unique adaptor that one had to purchase when changing the service provider. ${ }^{3}$ Participants made a total of 15 choices for which of the two firms they would buy from at different switching costs.

In Table 1, the bold numbers are the prices the subjects could get from each firm. These were presented in the middle columns (column 3 and column 4) for ease of comparison. The prices for the other consumer segment - the disadvantaged (old) consumers of DIFF - were also listed. The prices a subject (as a new customer of DIFF) could get were her current price at SAME (the bold number \$360) or the deal offer from DIFF (the bold number $\$ 280$, although the total cost would be higher due to the switching cost). Participants were asked to circle one of the two bold prices within each row, indicating which firm they chose in that specific scenario.

Consistent with Holt and Laury (2002) and Gonzalez and $\mathrm{Wu}$ (1999), we designed the table such that the total cost for the new customers of DIFF systematically changes from the 1st to the 15th choice, and hence one can observe at which point the decision maker switches from one firm to the other. This switching point captures the maximum amount a consumer would be willing to give up to resist DIFF. Thus, in Table 1, the switching cost increases by an incremental amount of $\$ 4$ from one choice to the next. ${ }^{4} \mathrm{~A}$ consumer who maximizes her own monetary payoff should choose DIFF (NetSpeed in Table 1) in choices 1-7, and switch to SAME (ConnStar) in choices 9-15. For choice 8, the consumer should be indifferent between the two and so would randomly pick one. Choosing SAME (ConnStar) before choice 8 is interpreted as resisting DIFF (NetSpeed) at a cost.

We counterbalanced firm names such that for half the subjects NetSpeed was DIFF and for the other half ConnStar was DIFF ("firm name effect"); for half of the participants

\footnotetext{
${ }^{3}$ Participants were told to ignore any hassle of switching (time, effort, and etc.) so that the only switching cost for them was the price of the adaptor.

${ }^{4}$ We vary the switching cost instead of the price of DIFF to keep the level of price discrimination constant across choice scenarios. This is also less confusing for subjects.
}

Table 1

Choice scenarios for new (advantaged) customers of DIFF. Study 1 and study 2.

\begin{tabular}{|c|c|c|c|c|}
\hline & \multicolumn{2}{|r|}{ NetSpeed } & \multicolumn{2}{|c|}{ ConnStar } \\
\hline & $\begin{array}{l}\text { Price to old } \\
\text { customers }\end{array}$ & $\begin{array}{l}\text { Price to new customers + } \\
\text { switching cost (adaptor } \\
\text { you need to buy on } \\
\text { your own) }\end{array}$ & $\begin{array}{l}\text { Price to old } \\
\text { customers }\end{array}$ & $\begin{array}{c}\text { Price to new } \\
\text { customers }\end{array}$ \\
\hline Choice 1 & $\$ 440$ & $\mathbf{\$ 2 8 0}+\$ 52=\$ 332$ & $\$ 360$ & $\$ 360$ \\
\hline Choice 2 & $\$ 440$ & $\mathbf{\$ 2 8 0}+\$ 56=\$ 336$ & $\$ 360$ & $\$ 360$ \\
\hline Choice 3 & $\$ 440$ & $\mathbf{\$ 2 8 0}+\$ 60=\$ 340$ & $\$ 360$ & $\$ 360$ \\
\hline Choice 4 & $\$ 44$ & $\mathbf{\$ 2 8 0}+\$ 64=\$ 344$ & $\$ 360$ & $\$ 360$ \\
\hline Choice 5 & $\$ 440$ & $\mathbf{\$ 2 8 0}+\$ 68=\$ 348$ & $\$ 360$ & $\$ 360$ \\
\hline Choice 6 & $\$ 440$ & $\mathbf{\$ 2 8 0}+\$ 72=\$ 352$ & $\$ 360$ & $\$ 360$ \\
\hline Choice 7 & $\$ 440$ & $\mathbf{\$ 2 8 0}+\$ 76=\$ 356$ & $\$ 360$ & $\$ 360$ \\
\hline Choice 8 & $\$ 440$ & $\mathbf{\$ 2 8 0}+\$ 80=\$ 360$ & $\$ 360$ & $\$ 360$ \\
\hline Choice 9 & $\$ 440$ & $\mathbf{\$ 2 8 0}+\$ 84=\$ 364$ & $\$ 360$ & $\$ 360$ \\
\hline Choice 10 & $\$ 440$ & $\mathbf{\$ 2 8 0}+\$ 88=\$ 368$ & $\$ 360$ & $\$ 360$ \\
\hline Choice 11 & $\$ 440$ & $\mathbf{\$ 2 8 0}+\$ 92=\$ 372$ & $\$ 360$ & $\$ 360$ \\
\hline Choice 12 & $\$ 440$ & $\mathbf{\$ 2 8 0}+\$ 96=\$ 376$ & $\$ 360$ & $\$ 360$ \\
\hline Choice 13 & $\$ 440$ & $\mathbf{\$ 2 8 0}+\$ 100=\$ 380$ & $\$ 360$ & $\$ 360$ \\
\hline Choice 14 & $\$ 440$ & $\mathbf{\$ 2 8 0}+\$ 104=\$ 384$ & $\$ 360$ & $\$ 360$ \\
\hline Choice 15 & $\$ 440$ & $\mathbf{\$ 2 8 0}+\$ 108=\$ 388$ & $\$ 360$ & $\$ 360$ \\
\hline Column 1 & Column 2 & Column 3 & Column 4 & Column 5 \\
\hline
\end{tabular}

DIFF was presented on the left side of the table and for the other half on the right ("order effect").

\section{Manipulations}

\section{Firm motive}

In the conditions with justified firm motive, the discriminating firm's pricing policy was justified as, "the firm (DIFF) wants to help new customers to pay any potential switching cost so that they will enjoy (DIFF)'s service more easily". In the conditions where firm motive was not justified, we simply did not describe any firm motive in the text.

\section{Salience of targeted pricing}

We manipulated high discrimination salience by inserting a flier into the questionnaire bearing the name of DIFF. The flyer only included pricing information of DIFF and a call for action:

\footnotetext{
Attention: NEW Customers

YOUR price: $\$ 280 /$ year

compared to \$440/year for our EXISTING customers

Switching to our service is hassle-free. Act now!
}

Although the flier did not provide the subjects with any information beyond what they already saw in the questionnaire, it made the targeted pricing policy more prominent for decision making. ${ }^{5}$

\footnotetext{
5 The salience manipulation was examined in a separate post-test. Using the scale: "Overall, how important was the fact that (DIFF) charged different prices to old and new customers in influencing your choice between the two firms? (1 being very unimportant-9 being very important)", we found that the mean in the high salience condition was 7.18 versus 5.58 in the low salience condition $(F(1,39)=6.16, p<.05)$, although the price table was exactly the same across these two conditions.
} 
Dependent variables used in study 1

There are two dependent variables - resistance and maximum loss. We also collect subjects' reasons for why they did what they do to measure perceptions of fairness.

\section{Resistance}

"Resistance" is a dummy variable that takes the value of one if the participant is willing to undergo some cost (however small) to stay away from DIFF. Otherwise, resistance takes the value of zero.

\section{Maximum loss}

Maximum loss represents the maximum amount of money a participant is willing to give up to refrain from purchasing from DIFF. Per the experiment design, the values of maximum loss can be one of the following: 0 (the participant being totally "rational" by choosing the lower total cost in every scenario), $4,8,12,16,20,24,28$ (the participant choosing to purchase from SAME in all 15 scenarios). For example, in Table 1 if the participant decides to stay with SAME for choices 3 through 15 , then she is willing to bear a maximum loss of $\$ 20$ (i.e., maximum loss $=20$ ).

\section{Perceived unfairness}

Participants' stated reasons for their choices were coded for whether these were related to ethics/fairness (1) or not (0). For example, some subjects stated that "I made my choices based on the fact that new and old customers are charged different prices (by DIFF). ..... It is not fair to entice people to come to your company and then overcharge them once you have their loyalty"; or "I don't like to support a company that discounts prices so heavily for new customers and charges a higher price to previous clients". For these subjects perceived unfairness was coded as 1 . When subjects' stated reasons were irrelevant to ethics/fairness, perceived unfairness took the value of 0 .

\section{Results of study 1}

Main and interaction effects of gender, age, firm name and order are not significant, and are dropped from our analyses. In Fig. 2a, we report the percentage of participants who chose to resist DIFF; and in Fig. $2 b$ the average amount of money participants were willing to forgo for resisting DIFF.

\section{Probability of participants resisting}

Overall, 49 out of the 227 participants in study 1 chose to purchase from SAME in situations where their cost would have been lower had they purchased from DIFF-this accounted for $21.59 \%$ of the subjects. This percentage is statistically greater than zero $(p<.01)$ and supports H1. A Logit model with resistance (yes/no) as the dependent variable and salience and firm motive as the independent variables (contrast-coded to be mean-centered) shows that both salience $(z=2.27 ; p<.05)$ and firm motive $(z=-3.27 ; p<.01)$ are significant, whereas their interaction is not $(p>.2)$. a

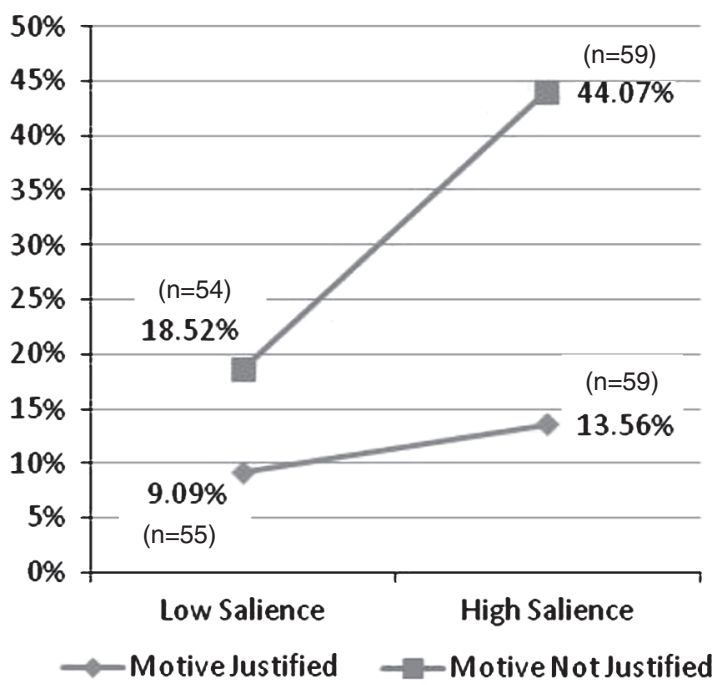

b

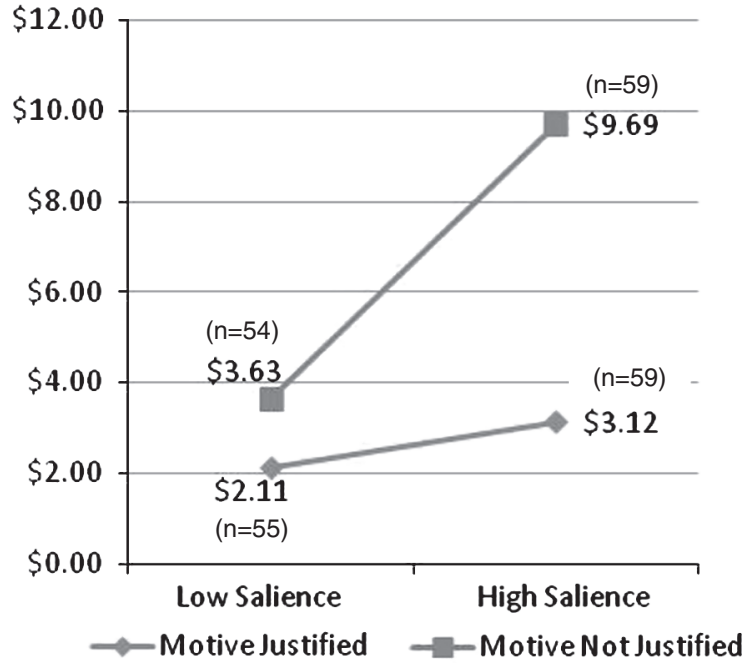

Fig. 2. a: Percentages of subjects who resisted DIFF (study 1). b: Average cost of resisting DIFF- maximum loss (study 1).

Consistent with $\mathrm{H} 2$, more participants resisted DIFF when the firm motive was not justified $(31.86 \%$ across the two notjustified cells) versus when it was $(11.40 \%$ across the two justified cells; $p<.01)$. Consistent with $\mathrm{H} 3$, a higher percentage of participants chose to resist DIFF when the price discrimination was more (28.81\% across the two high salience cells) versus less salient $(13.76 \%$ across the two low salience cells; $p<.01)$.

\section{Maximum loss}

As stated earlier, by design, the largest possible value for maximum loss is $\$ 28$. The mean of maximum loss for those who chose to resist DIFF (49 subjects) was $\$ 21.79$. In fact, 31 of the 49 subjects $(63.27 \%)$ were "right censored" at $\$ 28$ because they chose to stay with SAME for all 15 choices, i.e., 
they may have given up even more, but there was no more money to give up.

We conducted an ANOVA for the maximum loss participants were willing to bear as a function of discrimination salience and firm motive. The results show that there are significant main effects of discrimination salience $(F(1,223)=7.86, p<.01)$ and firm motive $(F(1,223)=10.30$, $p<.01)$ - when price discrimination is more salient and when firm motive is not justified, people give up more money to resist DIFF. The interaction between salience and motive is also significant $(F(1,223)=4.02, p<.05)$. Simple main effect analysis shows that discrimination salience is significant when firm motive is not justified $(M=\$ 9.69$ for salient versus $\mathrm{M}=\$ 3.63$ for not salient; $F(1,223)=11.50$, $p<.01)$, and not significant when firm motive is justified $(\mathrm{M}=\$ 3.12$ for salient versus $\mathrm{M}=\$ 2.11$ for not salient; $p>.5)$. Similarly, justification of firm motive has a significant effect on how much money people are willing to leave on the table when discrimination is more salient $(\mathrm{M}=\$ 3.12$ for justified versus $\mathrm{M}=\$ 9.69$ for not justified; $F(1,223)=14.15$, $p<.01)$, but not when discrimination is less salient $(\mathrm{M}=\$ 2.11$ for justified versus $\mathrm{M}=\$ 3.63$ for not justified; $p>.4$ ). Overall, these findings support our hypothesis on the effects of firm motive, discrimination salience, and their interaction $(\mathrm{H} 2 \sim \mathrm{H} 4)$.

\section{Mediation analysis}

The mediation process we have hypothesized is as follows:

\section{Salience/justification of discriminating policies $\rightarrow$ perception of unfairness $\rightarrow$ resistance to DIFF}

Therefore, we examine whether perceived unfairness mediates the impact of salience and of justification on maximum loss. Perceived unfairness was coded by two independent coders blind to the hypotheses, and the agreement rate was 95\%. Any disagreements were resolved by discussion. Analyses conducted through Preacher and Hayes's (2004) macro with 5000 bootstrapped samples indicate indirect only mediation (Zhao, Lynch, \& Chen, 2010) for both independent variables. In the salience model, controlling for justification, salience is shown to have a significant and positive total effect on maximum loss $(B=3.52, t(227)=2.78, p<.01)$. The indirect path of the effect of salience on maximum loss through perceived unfairness is also positive and significant, with the $95 \%$ confidence interval excluding zero (1.1632 to 4.4803$)$. The direct effect of salience on maximum loss is positive but not significant $(B=.83, t(227)=$ $.81, p>.4)$. Taken together, these results indicate an indirect only mediation for the effect of salience. A second model examines the mediation path for justification while controlling for salience. Results show that justification has a significant negative total effect on maximum loss $(B=-4.15, t(227)=$ $-3.27, p<.01)$. The indirect path of the effect of justification through perceived unfairness is significant and negative, with the $95 \%$ confidence interval excluding zero $(-4.5921$ to -1.1301$)$. The direct effect of justification on maximum loss is negative but not significant $(B=-1.39, t(227)=-1.35, p>.1)$, suggesting an indirect only mediation for the effect of justification on maximum loss.

Overall, the mediation analysis provides strong support for H5. ${ }^{6}$

\section{Discussion}

In study 1, we find strong support for all hypotheses. Advantaged consumers of targeted pricing bear a cost to resist a discriminating firm, and this resistance increases with lack of justification and higher salience of price discrimination. Perception of unfairness seems to drive the behavior. In study 1 , consumers did not give up real money. In study 2 , we test if they would.

\section{Study 2: Do consumers resist a discriminating firm even at a real cost to themselves?}

Since consumer resistance in study 1 was stronger in the condition where firm motive was not justified, in study 2 we focus on this condition, using a one-way between-subjects design with salience of price discrimination manipulated to be high or low. Ninety two undergraduate students from a Southwest university participated.

\section{Procedure}

Participants were fully informed of the monetary compensation. Before the cover story, they read "The choices that you make in this study will determine how much money you earn." Just before subjects made their decisions in the 15 choice scenarios, they read about how exactly their payment would be calculated. ${ }^{7}$ Basically, just like in the real world, the more a subject paid for a service, the less experimental money she was left with; so, the less money she received. The maximum possible loss to subjects who resisted DIFF was $\$ 3$ - that is, they would be paid $\$ 3$ less than subjects who made all "rational" payoff maximizing choices. The mean payment to our participants was $\$ 9.16$, and the range was $\$ 6.50-9.50$.

\section{Results of study 2}

No gender, order, age, or firm name main or interaction effects were found, and thus they are not discussed further. Fig. 3a and Fig. $3 \mathrm{~b}$ summarize the percentage of participants who chose to resist DIFF, and the average cost of resistance, respectively.

\footnotetext{
${ }^{6}$ Given the interaction between salience and justification, we also tested for mediated moderation following Muller, Judd, and Yzerbyt (2005). We tested whether salience's mediation process (that perceived unfairness mediates the effect of salience on resistance) is moderated by justification of the firm's motive, and found support for it. When firm motive is not justified, the impact of the mediator (perceived unfairness) on maximum loss is significantly stronger than when firm motive is justified.

${ }^{7}$ We use a formula to convert experimental money to actual payment. The formula was designed to give a feasible range of payment for each subject, while keeping the actual "maximum loss" of resisting DIFF substantial. Please see the Appendix for more details.
} 


\section{a}

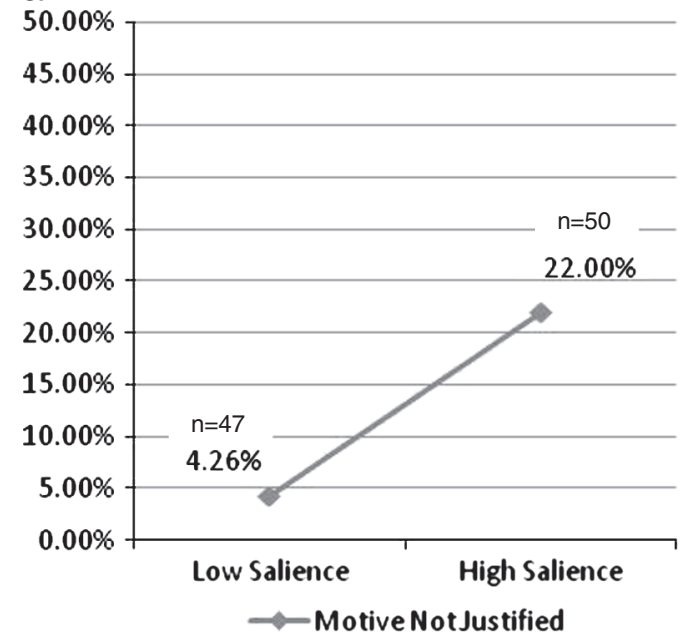

b

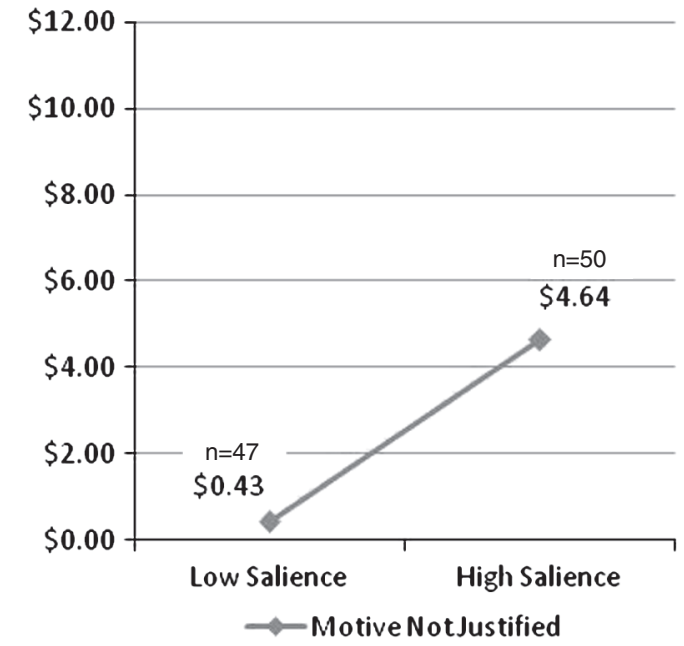

Fig. 3. a: Percentages of subjects who resisted DIFF (study 2). b: Average cost of resisting DIFF - maximum loss (study 2).

\section{Probability of participants resisting}

Consistent with $\mathrm{H} 1$, a significant percentage of subjects resisted DIFF at their own cost (13 out of 97 subjects, or $13.40 \%$; this is significantly different to zero, $p<.01$ ). A higher percentage of participants chose to resist DIFF in the high salience condition $(22.00 \%)$ versus the low salience condition (4.26\%). A simple Logit model with resistance (yes/no) as the dependent variable and salience as the independent variable shows that the salience effect is statistically significant $(z=2.31, p<.05)$, supporting $\mathrm{H} 3$.

\section{Maximum loss}

Subjects who resisted DIFF chose to bear close to the highest cost possible $(M=\$ 22.15)$. This again suggests that some people may sacrifice even more money if they were given the option to do so. Across all subjects (including those who did not resist DIFF), people were willing to bear a higher cost when the salience of discrimination was high $(M=\$ 4.64)$ than when it was low $(M=\$ 0.43 ; t(95)=2.38, p<.05)$. This pattern closely resembles what we found in study 1. In an ANOVA with maximum loss as the dependent variable and discrimination salience as the independent variable, we again observe a significant main effect of salience $(F(1,95)=5.66, p<.05)$.

\section{Mediation analysis}

When coding the perception of unfairness, the agreement rate between the two independent judges was $98 \%$ and any disagreements were resolved by discussion. We used the Preacher and Hayes's (2004) macro with 5000 bootstrapped samples to examine whether perceived unfairness mediates the impact of salience on maximum loss. Results show that salience has a significant and positive total effect $(B=4.21, t(97)=2.38, p<.05)$. The indirect path of the effect of salience on maximum loss through perceived unfairness is significant, with its $95 \%$ confidence interval excluding zero (.3893 to 6.2028). Moreover, the direct effect of salience on maximum loss is not significant $(B=1.15, t(97)=1.00, p>.3)$. Therefore, we find indirect only mediation, where subjects' perceived unfairness mediates the effect of discrimination salience on the maximum loss they are willing to bear in resisting DIFF.

\section{Discussion}

With real monetary payment to the participants, study 2 closely replicates the results of the non-payment conditions in study 1 . Hypotheses H1, H3 and H5 are again strongly supported in this study. Thus, we are more confident of our theory. While fewer consumers resisted the discriminating firm in this study than in study 1 where subjects were not paid, the percentage of consumers resisting is still meaningful.

\section{Study 3: Why do consumers resist the discriminating firm?}

Thirty-six evening MBA students from a Southwest university participated in study 3 for class credit. The study used a one-way design with two conditions. One condition ("SAME-DIFF" in Fig. 1b) used the same experimental set up as studies 1 and 2, where subjects were current customers of SAME and potential new customers of DIFF. We used the not-justified, salient context so that firm motive was not stated and a flyer from DIFF was given to subjects. The other condition ("SAME-SAME2") involved two non-discriminating firms. Subjects were current customers of SAME but could take advantage of a lower price offered by another nondiscriminating firm (SAME2). Subjects made only one decision in study 3. Table 2 presents the decision they faced in the experiment. The bold numbers in Table 2 represent the prices the subjects could get from each firm.

Subjects could save $\$ 15$ if they switched from their current firm (SAME) to the other firm (DIFF or SAME2, depending on the condition). The only difference between the two conditions was that the other firm (NetSpeed) price discriminated in SAME-DIFF but charged the same price to both segments in SAME-SAME2. All subjects provided reasons for their decision in an open-ended question. Also, in SAME-DIFF, we asked subjects to state how much they agreed with the 
Table 2

Choice scenario in study 3 .

\begin{tabular}{|c|c|c|c|}
\hline \multicolumn{2}{|c|}{ ConnStar (your current company) } & \multicolumn{2}{|l|}{ NetSpeed } \\
\hline $\begin{array}{l}\text { Price to } \\
\text { new } \\
\text { customers }\end{array}$ & $\begin{array}{l}\text { Price to old customers } \\
\text { (your total cost with } \\
\text { ConnStar) }\end{array}$ & $\begin{array}{l}\text { Price to new customers }+ \\
\text { switching cost (for adaptor)= } \\
\text { (your total cost with NetSpeed) }\end{array}$ & $\begin{array}{l}\text { Price to } \\
\text { old } \\
\text { customers }\end{array}$ \\
\hline \multicolumn{4}{|c|}{ SAME-DIFF condition: DIFF enticing customers away from SAME } \\
\hline$\$ 360$ & $\$ 360$ & $\mathbf{\$ 2 8 0}+\$ 65=\$ 345$ & $\$ 440$ \\
\hline \multicolumn{4}{|c|}{$\begin{array}{l}\text { SAME-SAME2 condition: another non-discrimination firm (SAME2) } \\
\text { offering a lowing price to all customers }\end{array}$} \\
\hline$\$ 360$ & $\$ 360$ & $\mathbf{\$ 2 8 0}+\$ 65=\$ 345$ & $\$ 280$ \\
\hline
\end{tabular}

following statements using a 7-point scale (anchored at 1 "strongly disagree", 4 "undecided", and 7 "strongly agree"):

(1) "I am confident that I will be satisfied with NetSpeed if I switch to it." (2) "I don't like the fact that NetSpeed is charging old customers a high price." (3) "In general, I try to avoid companies that are involved in unethical practices." (4) "I believe NetSpeed is using a lower introductory price to acquire new customers, which is a reasonable, common business practice."

The first three scales reflect expected future satisfaction, concern for disadvantaged consumers, and concern for ethics, respectively; the last scale serves as a control, because consumers may resist less if they perceive a discriminating pricing policy as an acceptable market norm.

\section{Results of study 3}

\section{Probability of participants resisting}

Overall resistance in study 3 was relatively high, likely because the subjects were (working) MBA students who could be less motivated by small amount of savings than undergraduate students. More importantly, when the deal was offered by DIFF, resistance rate was $73.68 \%$ (14 out of 19 subjects). When the same amount of savings was offered by a non-discriminating firm, the resistance rate was much lower at $41.18 \%$ ( 7 out of 17 subjects). This difference in resistance is caused by targeted pricing, and is significant at 0.05 level. $^{8}$

\section{Reasons for resistance}

Within the SAME-DIFF condition, we compare the means of the four motivation scales between the group of subjects who resisted DIFF versus those who did not resist and switched to DIFF. The results are presented in Table 3.

\footnotetext{
${ }^{8}$ We conducted the same mediation analysis as in study 1 and study 2 to test the following process: existence of discriminating policy $\rightarrow$ perception of unfairness (coded from open-ended question) $\rightarrow$ decision to stay or to switch We replicated the findings of the previous two studies, as the results indicated an indirect only mediation through the perception of unfairness.
}

Table 3

Reasons for resisting DIFF. Study 3 SAME-DIFF condition, N=19.

\begin{tabular}{|c|c|c|c|c|}
\hline & $\begin{array}{l}\text { Expected } \\
\text { satisfaction } \\
\text { with DIFF }\end{array}$ & $\begin{array}{l}\text { Concern } \\
\text { about } \\
\text { others }\end{array}$ & Ethics & $\begin{array}{l}\text { Pricing policy } \\
\text { perceived as } \\
\text { reasonable }\end{array}$ \\
\hline $\begin{array}{l}\text { Mean for the } 14 \text { subjects who } \\
\text { resisted DIFF }\end{array}$ & 3.21 & 6.43 & 6.29 & 4.29 \\
\hline $\begin{array}{l}\text { Mean for the } 5 \\
\text { subjects who } \\
\text { switched to DIFF }\end{array}$ & 4.80 & 5.00 & 6.00 & 6.00 \\
\hline$p$-Value & $0.023 * *$ & $0.060 *$ & 0.537 & $0.039 * *$ \\
\hline
\end{tabular}

Both expected future satisfaction with DIFF and concerns for disadvantaged consumers seem to drive consumer resistance to DIFF. The overall propensity for ethics does not seem to affect this decision - the ethics scale receiving a high score both from switchers and non-switchers; almost everyone, expectedly, claimed that they would not interact with an unethical firm. Moreover, as expected, those who believed DIFF was adopting a commonly-used introductory pricing policy resisted the firm less.

\section{Conclusions and future research}

\section{General discussion}

In three experiments, we show that targeted pricing - a common marketing tool-can evoke social consciousness for a subset of advantaged consumers so that they are willing to incur a cost for resistance. We notice that the proportion of respondents who resisted the lower priced offer at a real financial cost (e.g., in study 2) is relatively low. However, this is still a meaningful subset of respondents, especially considering that individuals can be much more involved and motivated in their real-life choices.

It is important to note that consumer resistance is stronger when the savings are made more salient in promotional materials. This presents a dilemma for marketers who generally believe that making price deals salient should entice more people to switch to them. Resistance is also higher when the firm's motivation for price discrimination is not justified by it, suggesting that firms may be able to reduce the negative reactions of consumers by providing clearer indication of their motives when offering the savings.

Our research also reveals that perceived unfairness mediates the effect of justification and salience on resistance. In study 3 , we find that those who resisted the price deal were more concerned about the group of customers whom the firm discriminated against than were those who switched to the discriminating firm. Further, the resisters expected to have lower satisfaction with the discriminating firm-these consumers may have derived negative inferences (e.g., about the firm's level of customer service) from the pricing policy of the discriminating firm. 


\section{Future research}

Consumers often need to balance their moral concerns against their materialistic desires in the marketplace (Alwitt \& Pitts, 1996; Bian \& Keller, 1999; Folkes \& Kamins, 1999; Irwin, 1999). Our research identifies two moderators (justification and salience) of resistance to perceived unfairness. Future research should explore other conditions where ethical concerns of consumers would trump their self-interested behavior.

Consumers' perception of fairness can be shaped by marketplace norms. We find that when respondents perceived the price discrimination as a temporary introductory price and common business practice, they resisted the discriminating firm less. In all our experiments, it was evident that existing and new customers are paying different prices. It is possible that the results may weaken when the discriminatory pricing is not so evident. Future research could test the hypotheses in a situation where there are low introductory prices to new customers but prices to existing customers are not mentioned; or in a situation where new customers are told what prices will be when they join and also after an introductory period. It would also be interesting to explore how pricing policies vary across industries and become the accepted norm, decreasing consumer resistance, and the effect of the subsequent marketplace norms on consumer behavior.

Our results indicate that common marketing tools may be perceived as social violations and have negative consequences, and that firms' behaviors do not have to be egregious for such negative responses. We hope that our work spurs more research on how other commonly used marketing tools can invoke social consciousness and affect consumer behavior. Our research also suggests that the perceptions of fairness, and, more generally, the value attached to maintaining one's moral standards should be considered in marketing models.

\section{Appendix A. Payment in study 2}

\section{How much money will you make from this study?}

You will be asked to make 15 choices between these two firms in 15 different scenarios. Since you are an "old customer" of ConnStar but a (potential) "new customer" for NetSpeed, you should look at the bolded numbers in the table on next page for the prices you can get from the two firms. Your decisions on which firm to buy from will determine the amount of money you earn.

Specifically, we add up all the prices you pay to the firms (plus switching cost, if applicable) and divide them by 15 (i.e., the number of choices you make). This gives us your "average cost" for the high-speed Internet service. We will then give you:

\section{\$(376-average cost) /2.5,}

in cash. For example, if your average cost is $\$ 360$, we will pay you $\$ 6.40$ (calculated from the above formula).
Please note that when you choose a firm's service, the firm earns additional money from you. The more you pay a firm, the less money you make and the more money the firm makes. The other firm, the one you do not choose, makes no money from you for that choice.

\section{References}

Alwitt, L. F., \& Pitts, R. E. (1996). Predicting purchase intentions for an environmentally sensitive product. Journal of Consumer Psychology, 5(1), 49-64.

Bechwati, N. N., \& Morrin, M. (2003). Outraged consumers: Getting even at the expense of getting a good deal. Journal of Consumer Psychology, 13(4), 440-453.

Bian, W., \& Keller, L. R. (1999). Patterns of fairness judgments in North America and the People's Republic of China. Journal of Consumer Psychology, 8(3), 301-320.

Blodgett, J. G., Granbois, D. H., \& Walters, R. G. (1993). The effects of perceived justice on complainants' negative word-of-mouth behavior and patronage intentions. Journal of Retailing, 69(4), 399-428.

Bolton, G. E., \& Ockenfels, A. (2000). ERC: A theory of equity, reciprocity, and competition. American Economic Review, 90(1), 166-193.

Bolton, L. E., Warlop, L., \& Alba, J. W. (2003). Consumer perceptions of price (un)fairness. Journal of Consumer Research, 29(4), 474-491.

Brown, C. L., \& Krishna, A. (2004). The skeptical shopper: A metacognitive account for the effects of default options on choice. Journal of Consumer Research, 31(3), 529-539.

Campbell, M. C. (1999). Perceptions of price unfairness: Antecedents and consequences. Journal of Marketing Research, 36(2), 187-199.

Campbell, M. C. (2007). 'Says who?!' How the source of price information and affect influence perceived price (un)fairness. Journal of Marketing Research, 44(2), 261-271.

Darke, P. R., \& Dahl, D. W. (2003). Fairness and discounts: The subjective value of a bargain. Journal of Consumer Psychology, 13(3), 328-338.

Fehr, E., \& Gächter, S. (1997). How effective are trust- and reciprocity-based incentives? In A. Ben-Ner, \& L. Putterman (Eds.), Economics, values, and organization. Cambridge: Cambridge University Press.

Fehr, E., Gächter, S., \& Kirchsteiger, G. (1997). Reciprocity as a contract enforcement device: Experimental evidence. Econometrica, 65(4), $833-860$.

Feinberg, F. M., Krishna, A., \& Zhang, Z. J. (2002). Do we care what others get? A behaviorist approach to targeted promotions. Journal of Marketing Research, 39(3), 277-291.

Fitzgerald, M. (1993). Boycott. Editor and publisher, 126. (pp. 77) (June 12).

Folkes, V. S., \& Kamins, M. A. (1999). Effects of information about firms' ethical and unethical actions on consumers' attitudes. Journal of Consumer Psychology, 8(3), 243-259.

Forehand, M. R., \& Grier, S. (2003). When is honesty the best policy? The effect of stated company intent on consumer skepticism. Journal of Consumer Psychology, 13(3), 349-356.

Friestad, M., \& Wright, P. (1994). The persuasion knowledge model: How people cope with persuasion attempts. Journal of Consumer Research, 21(1), $1-31$.

Fudenberg, D., \& Tirole, J. (2000). Customer poaching and brand switching. RAND Journal of Economics, 31(4), 634-657.

Gonzalez, R., \& Wu, G. (1999). On the shape of the probability weighting function. Cognitive Psychology, 38, 129-166.

Holt, C., \& Laury, S. (2002). Risk aversion and incentive effects. American Economic Review, 92(5), 1644-1656.

Irwin, J. R. (1999). Introduction to the special issue on ethical trade-offs in consumer decision making. Journal of Consumer Psychology, 8(3), 211-213.

John, A., \& Klein, J. G. (2003). The boycott puzzle: Consumer motivations for purchase sacrifice. Management Science, 49(9), 1196-1209.

Klein, J. G., Smith, N. C., \& John, A. (2004). Why we boycott: Consumer motivations for boycott participation. Journal of Marketing, 68(3), 92-109. 
Krishna, A., \& Johar, G. V. (1996). Consumer perception of deals: Biasing effects of varying deal prices. Journal of Experimental Psychology: Applied, 2(3), 187-206.

Lalwani, A. K., \& Monroe, K. B. (2005). A reexamination of frequency-depth effects in consumer price judgments. Journal of Consumer Research, 32(3), 480-485.

Muller, D., Judd, C. M., \& Yzerbyt, V. Y. (2005). When moderation is mediated and mediation is moderated. Journal of Personality and Social Psychology, 89(6), 852-863.

Preacher, K. J., \& Hayes, A. F. (2004). SPSS and SAS procedures for estimating indirect effects in simple mediation models. Behavior Research Methods, Instruments, and Computers, 36(4), 717-731.

Richins, M. L. (1983). Negative word-of-mouth by dissatisfied consumers: A pilot study. Journal of Marketing, 47(1), 68-78.
Sen, S., Gurhan-Canli, Z., \& Morwitz, V. (2001). Withholding consumption: A social dilemma perspective on consumer boycotts. Journal of Consumer Research, 28(3), 399-417.

Taylor, C. R. (2003). Supplier surfing: Competition and consumer behavior in subscription markets. RAND Journal of Economics, 34(2), 223-246.

Villas-Boas, J. M. (1999). Dynamic competition with customer recognition. RAND Journal of Economics, 30(4), 604-631.

Xia, L., Monroe, K. B., \& Cox, J. L. (2004). The price is unfair! A conceptual framework of price fairness perceptions. Journal of Marketing, 68(4), $1-15$.

Zhao, X., Lynch, J. G., \& Chen, Q. (2010). Reconsidering Baron and Kenny: Myths and truths about mediation analysis. Journal of Consumer Research, 37(2), 197-206. 